\title{
Long-term predictive value of acute kidney injury classification in diffuse proliferative lupus nephritis with acute kidney injury
}

\author{
Tianxin Chen ${ }^{1 *} \mathbb{D}$, Ying Zhou', Jianna Zhang ${ }^{1}$, Chaosheng Chen ${ }^{1}$ and Jingye Pan $^{2}$
}

\begin{abstract}
Background: The long-term predictive ability of acute kidney injury (AKI) classification based on "Kidney Disease: Improving Global Outcomes"(KDIGO) AKI diagnosis criteria has not been clinically validated in diffuse proliferative lupus nephritis (DPLN) patients with AKI. Our objective was to assess the long-term predictive value of KDIGO AKI classification in DPLN patients with AKI.
\end{abstract}

Methods: Retrospective cohort study was conducted by reviewing medical records of biopsy-proven DPLN patients with AKI from the First Affiliated Hospital of Wenzhou Medical University between Jan 1, 2000 and Dec 31, 2014. Multivariate Cox regression and survival analysis were performed.

Results: One hundred sixty-seven DPLN patients were enrolled,82(49\%) patients were normal renal function (No AKI), 40(24\%) patients entered AKI-1 stage (AKI-1), 26(16\%) patients entered AKI-2 stage (AKI-2) and 19(16\%) patients entered AKI-3 stage (AKI-3). The mean follow-up of all patients was $5.1 \pm 3.8$ years. The patient survival without ESRD of all patients was $86 \%$ at 5 years and $79 \%$ at 10 years. The patient survival rate without ESRD at $10 \mathrm{yr}$ was $94.5 \%$ for No AKI patients, $81.8 \%$ for AKI-1 patients, $44.9 \%$ for AKI-2 patients and 14.6\% for AKI-3 patients. The area under the ROC curve for KDIGO AKI classification to predict the primary end point was 0.83 (95\% Cl: 0.73-0.93) $(P<0.001)$. In Cox regression analysis, AKI stage was independently associated with primary endpoint, with an adjusted hazard ratio (HR) of 3.8(95\% Cl 2.1-6.7, P<0.001).

Conclusion: Severity of AKI based on KDIGO AKI category was associated with progression to ESRD in DPLN patients. Analytical data also confirmed the good discriminative power of the KDIGO AKI classification system for predicting long-term prognosis of DPLN patients with AKI.

Keywords: Acute kidney injury, Lupus nephritis, KDIGO, ESRD, ACR;SLE

\section{Background}

Lupus nephritis (LN) represents a common organ involvement in patients with systemic lupus erythematosus (SLE), and diffuse proliferative lupus nephritis (DPLN) remains a major cause of renal failure and mortality among patients with SLE [1-4]. Clinical reports found that complete or partial remission, nephritic flares and renal function at baseline were predictors of long-term renal outcome in LN [5-7]. Acute kidney injury (AKI) is a common complication of LN. 66 (20.5\%) patients were

\footnotetext{
*Correspondence: ctxzj@@163.com

'Department of Nephrology, The First Affiliated Hospital of Wenzhou Medical University, Wenzhou 325000, Zhejian Province, People's Republic of China Full list of author information is available at the end of the article
}

identified as AKI among 322 Chinese LN patients in a recent report [8]. Fifty patients with acute renal failure (ARF) of 127 pediatric LN patients were identified in a prospective observational study [9]. Our previous study showed 54\% DPLN patients had AKI and AKI severity was associated with an increase in renal function progression [10]. However, the long-term predictive ability of AKI classification based on "Kidney Disease: Improving Global Outcomes" (KDIGO) AKI diagnosis criteria has not been clinically validated in DPLN patients with AKI [11]. In recent years, the focus on the immediate complications and survival of AKI has been followed by a growing awareness of adverse long-term outcomes [12]. To assess the long-term predictive value of KDIGO

(C) The Author(s). 2020 Open Access This article is distributed under the terms of the Creative Commons Attribution 4.0 International License (http://creativecommons.org/licenses/by/4.0/), which permits unrestricted use, distribution, and reproduction in any medium, provided you give appropriate credit to the original author(s) and the source, provide a link to the Creative Commons license, and indicate if changes were made. The Creative Commons Public Domain Dedication waiver (http://creativecommons.org/publicdomain/zero/1.0/) applies to the data made available in this article, unless otherwise stated. 
AKI classification for patient and renal survival in DPLN patients, we now report the results of our extended follow-up of a large cohort of Chinese DPLN patients with AKI.

\section{Methods}

This is a retrospective observational study. The Ethics Committee of the First Affiliated Hospital of Wenzhou Medical University waived the need for an informed consent. Data were collected anonymously.

\section{Participants}

All biopsy-proven DPLN patients admitted to the First Affiliated Hospital of Wenzhou Medical University between Jan 1, 2000 and Dec 31, 2014 were enrolled retrospectively. The entry criteria: patients were diagnosed as SLE according to American College of Rheumatology (ACR) criteria [13] and had a histological diagnosis of DPLN (ISN/RPS classification: LN type IV or type IV + V) [14]. Patients with pre-renal AKI, post-renal AKI, renal tubular necrosis and acute interstitial nephritis; chronic renal insufficiency and obvious chronic histological changes were excluded. KDIGO AKI stages (Table 1) were classified according to serum creatinine (Scr) values on the first day of admission. One hundred sixty-seven DPLN patients were enrolled, 82 patients were normal renal function (No AKI), 40 patients entered AKI-1 stage (AKI-1), 26 patients entered AKI-2 stage (AKI-2) and 19 patients entered AKI-3 stage (AKI$3)$.

\section{Treatment protocol}

Therapeutic decisions were taken in view of clinical conditions and the renal biopsy results. All patients initially received high dose prednisone $(1 \mathrm{mg} / \mathrm{kg}$ per day) or intravenous methylprednisolone (MP) pulses $(0.5-1.0 \mathrm{~g} /$ day for three consecutive days) followed by oral prednisone $0.5-1.0 \mathrm{mg} / \mathrm{kg}$ per day. After the initial 4 weeks of treatment, the dosage of prednisone was gradually tapered to $10-15 \mathrm{mg} /$ day during 24 weeks in patients who improved clinically. Another course of intravenous MP pulses or the initial high-dosage prednisone for an additional 4 weeks were continued in patients with worsening renal function. Patients received intermittent

\section{Table 1 Classification and staging of KDIGO criteria}

\begin{tabular}{ll}
\hline Stage & KDIGO serum creatinine criteria \\
\hline 1 & 1.5 to 1.9 times baseline or $\geq 0.3 \mathrm{mg} / \mathrm{dl}(\geq 26.5 \mu \mathrm{mol} / \mathrm{l})$ increase \\
2 & 2.0 to 2.9 times baseline \\
3 & $\begin{array}{l}3.0 \text { times baseline or increase in serum creatinine to } \geq 4.0 \mathrm{mg} / \mathrm{dl} \\
(\geq 353.6 \mu \mathrm{mol} / \mathrm{l}) \text { or initiation of renal replacement therapy or in } \\
\text { patients }<18 \text { years a decrease in eGFR to }<35 \mathrm{ml} / \mathrm{minute} \\
\text { per } 1.73 \mathrm{~m}^{2}\end{array}$ \\
\hline
\end{tabular}

Scr Serum creatinine, eGFR estimated glomerular filtration rate intravenous cyclophosphamide (CTX) or mycophenolate mofetil (MMF) therapy. Maintenance therapy included low dose prednisone, hydroxychloroquine, and MMF.

\section{Data collection}

Demographic an clinical records, renal pathological changes and laboratory test reports were retrieved. Demographic records included age, sex and duration of hospital stay. Clinical data included medical history, physical examination, diagnosis, medications and renal replacement therapy. Pathological data included microscopic and immunofluorescent characteristics. Laboratory data mainly included Scr, serum albumin, hemoglobin $(\mathrm{Hb}), 24-\mathrm{h}$ proteinuria, anti-dsDNA antibody $(\mathrm{Ab})$ and serum complement component $3(\mathrm{C} 3)$. Scr was used to calculate the estimated glomerular filtration rate (eGFR) assessed by the Chronic Kidney Disease Epidemiology research group (CKD-EPI) equation [15].

\section{Study end point and follow-up}

The primary study end point was death and ESRD. ESRD was defined as maintenance dialysis (hemodialysis or peritoneal dialysis) more than 3 months or renal transplantation. Scr was measured at least once weekly in hospital. Follow-ups were carried out in outpatient service and Scr was measured monthly after patients discharged from hospital.

\section{Statistical methods}

Values of continuous variables were reported as means \pm standard deviation (SD), and compared by analysis of variance (ANOVA) test. Categorical data were reported as percentages and tested using the chi-square test. The survival analysis was based on the Kaplan-Meier curve with subjects censored for death and ESRD. A log-rank test was used to compare the survival rates among four groups. A multivariate Cox regression analysis was used to evaluate mortality and ESRD risk. Results were expressed as a hazard ratio (HR) with $95 \%$ confidence intervals (CIs). Discriminative power of AKI stage was assessed using the area under a receiver operating characteristic (AUROC) curve. All statistical tests were twotailed; statistical significance was defined as $P \leq 0.05$. Data were analyzed using the SPSS version 16 (SPSS, Inc., Chicago, IL, USA).

\section{Results}

\section{Baseline clinical characteristics}

One hundred sixty-seven DPLN patients were enrolled. $49 \%$ of patients were No AKI, 24\% entered AKI-1,16\% entered AKI-2 and 11\% entered AKI-3 according to KDIGO AKI class criteria on the first day of admission. The baseline clinical characteristics on the basis of AKI stage are shown in Table 2 . There were no significant 
Table 2 Baseline clinical and serologic characteristics

\begin{tabular}{|c|c|c|c|c|c|}
\hline Parameter & no AKI & $\mathrm{AKI}-1$ & AKI-2 & AKI-3 & $P$ \\
\hline $\mathrm{n}(\%)$ & $82(49)$ & $40(24)$ & $26(16)$ & $19(11)$ & \\
\hline Age $(y r$, mean $\pm S D)$ & $29 \pm 9$ & $30 \pm 10$ & $32 \pm 12$ & $30 \pm 12$ & 0.44 \\
\hline Female(n[\%]) & $76(93)$ & $39(98)$ & $23(89)$ & $17(90)$ & 0.49 \\
\hline $\begin{array}{l}\text { systolic BP } \\
(\mathrm{mmHg} ; \mathrm{mean} \pm \mathrm{SD})\end{array}$ & $132 \pm 23$ & $\begin{array}{l}141 \pm \\
22\end{array}$ & $\begin{array}{l}139 \pm \\
24\end{array}$ & $\begin{array}{l}150 \pm \\
28\end{array}$ & 0.02 \\
\hline $\begin{array}{l}\text { diastolic BP (mmHg; } \\
\text { mean } \pm \text { SD) }\end{array}$ & $86 \pm 16$ & $91 \pm 15$ & $88 \pm 16$ & $98 \pm 14$ & 0.01 \\
\hline Scr (mg/dl;mean \pm SD) & $0.8 \pm 0.1$ & $\begin{array}{l}1.4 \pm \\
0.1\end{array}$ & $\begin{array}{l}2.1 \pm \\
0.4\end{array}$ & $\begin{array}{l}5.9 \pm \\
5.0\end{array}$ & $<0.01$ \\
\hline $\begin{array}{l}\text { Serum Alb(g/dl;mean } \pm \\
\text { SD) }\end{array}$ & $2.7 \pm 0.7$ & $\begin{array}{l}2.5 \pm \\
0.6\end{array}$ & $\begin{array}{l}2.4 \pm \\
0.6\end{array}$ & $\begin{array}{l}2.3 \pm \\
0.5\end{array}$ & 0.01 \\
\hline $\mathrm{Hb}(\mathrm{g} / \mathrm{dl} ;$ mean $\pm \mathrm{SD})$ & $\begin{array}{l}10.2 \pm \\
2.1\end{array}$ & $\begin{array}{l}9.6 \pm \\
2.1\end{array}$ & $\begin{array}{l}8.8 \pm \\
2.1\end{array}$ & $\begin{array}{l}7.4 \pm \\
1.7\end{array}$ & $<0.01$ \\
\hline $\begin{array}{l}\text { Anti-dsDNA Ab } \\
\text { positivity(n[\%]) }\end{array}$ & $64(78)$ & $29(73)$ & $21(81)$ & $15(79)$ & 0.86 \\
\hline $\begin{array}{l}\text { nephrotic } \\
\text { syndrome(n[\%]) }\end{array}$ & $55(67)$ & $33(83)$ & $23(89)$ & $17(90)$ & 0.03 \\
\hline $\mathrm{C}_{3}(\mathrm{mg} / \mathrm{dl} ;$ mean $\pm \mathrm{SD})$ & $0.4 \pm 0.2$ & $\begin{array}{l}0.4 \pm \\
0.2\end{array}$ & $\begin{array}{l}0.3 \pm \\
0.2\end{array}$ & $\begin{array}{l}0.4 \pm \\
0.1\end{array}$ & 0.76 \\
\hline $\begin{array}{l}\text { Proteinuria(g/d;mean } \pm \\
\text { SD) }\end{array}$ & $3.7 \pm 2.3$ & $\begin{array}{l}4.8 \pm \\
3.0\end{array}$ & $\begin{array}{l}4.5 \pm \\
2.8\end{array}$ & $\begin{array}{l}5.7 \pm \\
4.7\end{array}$ & 0.03 \\
\hline $\begin{array}{l}\text { eGFR (ml/min;mean } \pm \\
\mathrm{SD})\end{array}$ & $92 \pm 23$ & $49 \pm 6$ & $32 \pm 7$ & $17 \pm 18$ & $<0.01$ \\
\hline MP pulse,(n[\%]) & $20(24)$ & $16(40)$ & $16(62)$ & $13(68)$ & $<0.01$ \\
\hline$M M F,(n[\%])$ & $34(42)$ & $15(38)$ & $11(42)$ & $6(32)$ & 0.85 \\
\hline $\mathrm{CTX},(\mathrm{n}[\%])$ & $58(73)$ & $26(65)$ & $20(77)$ & $11(68)$ & 0.47 \\
\hline
\end{tabular}

Scr serum creatinine, Alb albumin, $\mathrm{Hb}$ hemoglobin, $A b$ antibody, $C 3$

complement component 3; eGFR mofetil, CTX cyclophosphamide

differences in age, gender, anti-dsDNA Ab, C3 or cytotoxic agents treatment among four groups at baseline; however, the mean level of Scr, eGFR, blood pressure, proteinuria, serum albumin, and $\mathrm{Hb}$ at baseline was significantly different among four groups. The rate of MP pulse treatment was 24, 40, 62 and $68 \%$ in group No AKI, AKI-1, AKI-2 and AKI-3 $(P<0.01)$.

\section{Renal histological features}

The histological features on the basis ISN/RPS are shown in Table 3. Patients with AKI-2 and AKI-3 were more likely to have category $\operatorname{global}(\mathrm{G})$ lesions than No AKI patients; the proportion of patients with type IV $+\mathrm{V}$ was significantly lower in group AKI-2 and AKI-3 compared with group No AKI; the proportion of patients with the active plus chronic lesions and great crescents (involves $>50 \%$ of the circumference of Bowman's capsule) $\geq 50 \%$ was significantly higher in group AKI-3 than the other three groups.

\section{Primary endpoint outcomes}

The mean follow-up of all patients was $5.1 \pm 3.8$ years. The patient survival without ESRD of all patients was
Table 3 The histological features on the basis of ISN/RPS

\begin{tabular}{llllll}
\hline Parameter & no AKI & AKI-1 & AKI-2 & AKI-3 & $P$ \\
\hline n(\%) & $82(49)$ & $40(24)$ & $26(16)$ & $19(11)$ & \\
ISN/RPS LN IV + V & $30(37)$ & $14(35)$ & $5(19)$ & $1(5)$ & 0.03 \\
ISN/RPS IV-G(n[\%]) & $61(74)$ & $33(83)$ & $24(92)$ & $18(95)$ & 0.07 \\
ISN/RPS IV-A + C(n[\%]) & $12(15)$ & $15(38)$ & $6(23)$ & $9(47)$ & $<0.01$ \\
Great crescents & & & & & \\
$<30 \%(n[\%])$ & $69(84)$ & $33(83)$ & $19(73)$ & $5(26)$ & \\
$\geq 30,<50 \%(n[\%])$ & $10(12)$ & $4(10)$ & $3(12)$ & $3(16)$ & \\
$\geq 50 \%(n[\%])$ & $3(4)$ & $3(7)$ & $4(15)$ & $11(58)$ & $<0.01$ \\
\hline ISNRPS & & &
\end{tabular}

ISN/RPS International Society of Nephrology and Renal Pathology Society, IV-G diffuse global lesions; Great crescent is one of those extracapillary lesions that involves $>50 \%$ of the circumference of Bowman's capsule; great crescents $\geq 50 \%$, refers to patients with $>50 \%$ of the glomeruli containing great crescents

$86 \%$ at 5 years and $79 \%$ at 10 years. The incidence of ESRD and death increased with advancing KDIGO AKI stage. The patient survival rate without ESRD at $10 \mathrm{yr}$ was $94.5 \%$ for No AKI patients, $81.8 \%$ for AKI-1 patients, $44.9 \%$ for AKI-2 patients and $14.6 \%$ for AKI-3 patients. Patient survival without ESRD was significantly worse for patients with AKI-2 (mean, $112 \pm 15$ mon) and AKI-3 (mean, $37 \pm 9$ mon) compared with No AKI (mean, $169 \pm 5$ mon, $P<0.001$ ); Patient survival without ESRD was more likely to have short survival time for patients with AKI-1(mean, $137 \pm 7$ mon,) than No AKI (mean, $169 \pm 5$ mon, $P=0.08)$. (Fig. 1 ).

The ROC curve model represents the true-positive and false-positive rates for progression to primary end point and the area under the ROC curve for progression to primary end point was 0.83 (95\% CI: $0.73-0.93)(P<$ 0.001) (Fig. 2). AKI-2 stage was the best cut-offs for clinical use and had higher sensitivity or better ability to identify DPLN patients with primary outcome(the sensitivity was $74 \%$ and specificity was $82 \%$ ).

There was a significant dose-dependent relationship between the severity of AKI and the primary endpoint. In Cox regression analysis (Table 4), AKI stage was independently associated with primary endpoint, with an adjusted HR of 3.8(95\% CI 2.1-6.7, $P<0.001)$. Great crescent $>30 \%(\mathrm{HR}=2.1,95 \%$ CI 1.2-3.6, $P<0.008)$, $\mathrm{Hb}<8.0 \mathrm{~g} / \mathrm{dl}(\mathrm{HR}=4.8,95 \% \mathrm{CI} 1.6-14.0, P<0.005)$ and proteinuria $>3.0 \mathrm{~g} / \mathrm{d} \quad(\mathrm{HR}=5.1, \quad 95 \%$ CI $1.5-17.1, \quad P<$ $0.008)$ were also the main predictors of ESRD.

\section{Discussion}

There are more options for treatments in recent years, but the efficacy does not appear to be improved obviously in DPLN patients. The patient and kidney 10 -year survival rate of DPLN patients was $79 \%$ in 1997and $82.8 \%$ in 2006 [16, 17]. During a mean follow-up of $5.1 \pm$ 3.8 years in our population, the patient survival without ESRD of all DPLN patients was $79 \%$ at 10 years. Current 


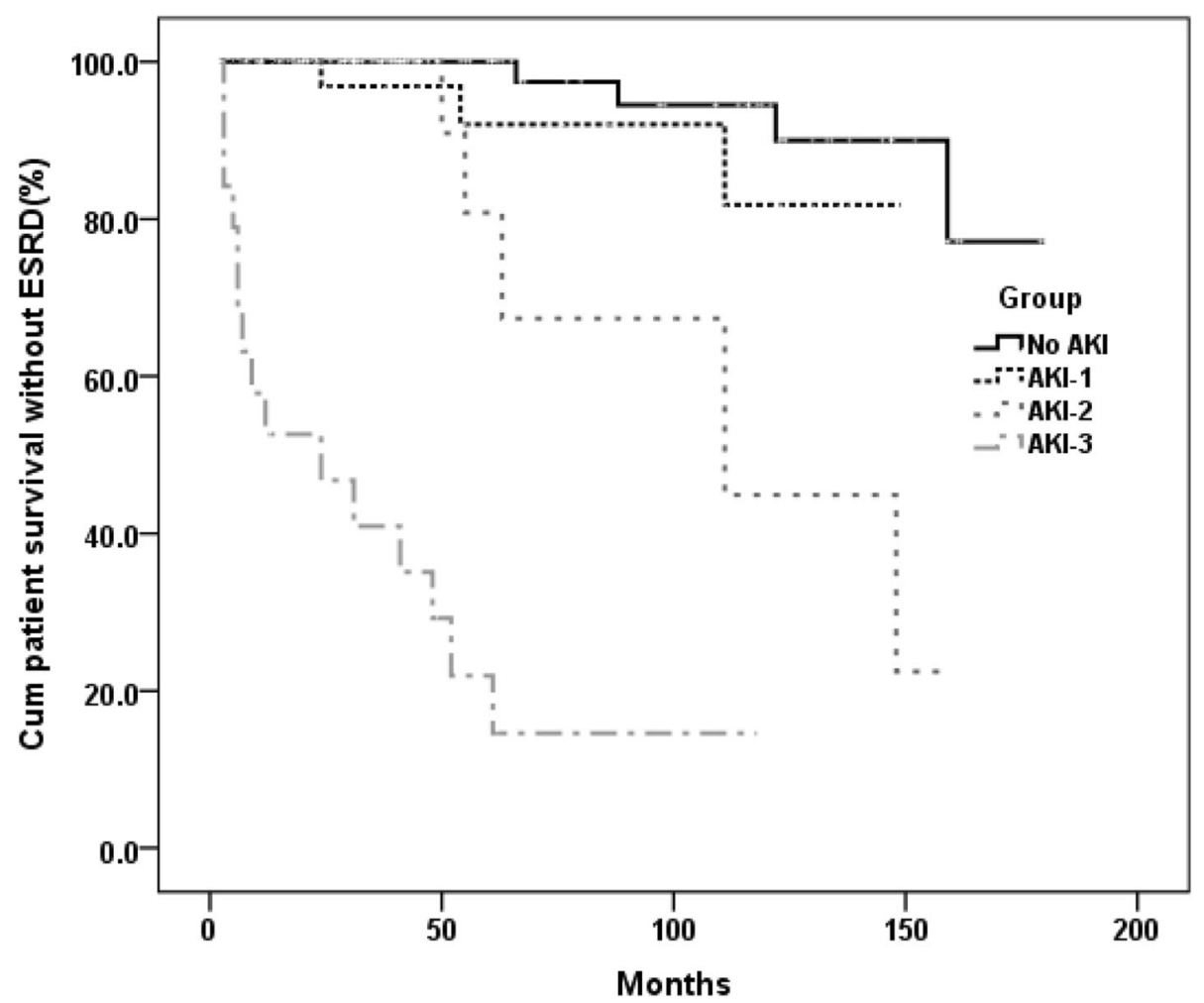

Fig. 1 Patient survival without ESRD in DPLN patients based on AKI stage $(P<0.001$, overal). AKI-1 versus No AKI: $137 \pm 7$ mon vs $169 \pm 5$ mon, $p=0.209 ;$ AKI- 2 versus No AKl: $112 \pm 15$ mon vs $169 \pm 5$ mon, $P<0.001$; AKl-3 versus No AKI: $37 \pm 9$ mon vs $169 \pm 5$ mon $P<0.001$. AKl-2 versus AKI-1: $112 \pm 15$ mon vs $137 \pm 7$ mon $p=0.089$; AKI- 3 versus AKI- $1: 37 \pm 9$ mon vs $137 \pm 7$ mon, $P<0.001$. AKI- 3 versus AKI- $2: 37 \pm 9$ mon vs $112 \pm 15$ mon, $P<0.001$

treatment approach for $\mathrm{LN}$, as outlined in the recommendations by international medical associations including European League Against Rheumatism (EULAR), the ACR or KDIGO, still was corticosteroids in combination with CTX or MMF as induction treatment and azathioprine or MMF as maintenance treatment [18-20]. No consensus has been reached on the role of calcineurin inhibitors (CNIs) and rituximab so far. The dose of corticosteroids and cytotoxic agents is mostly eminencebased rather than evidence-based. The initial dose of prednisone in proliferative LN was different from 0.5 to1.0 $\mathrm{mg} / \mathrm{kg}$ per day, preceded by three iv. pulses of MP (the dose from $6.6 \mathrm{mg} / \mathrm{kg}$ per day to $1.0 \mathrm{~g} /$ day) in some clinical trials [21-26]. MP pulse regimen was preferred for severe clinical conditions of proliferative LN by nephrologists. In our study, 68\% patients in group AKI-3 and $62 \%$ in group AKI-2 had MP pulse therapy, only $24 \%$ in group No AKI.

The patient survival rate without ESRD at $10 \mathrm{yr}$ was 94.5\% in No AKI patients, which was similar with the result of other reports [3, 27, 28]. More than $60 \%$ DPLN patients with AKI-2 and AKI-3 stage received intravenous MP pulse therapy, but the renal survival rate can't be improved effectively. The patient survival rate without ESRD at $10 \mathrm{yr}$ was $44.9 \%$ for AKI-2 patients and only $14.6 \%$ for AKI-3 patients. DPLN with AKI had poor short-term renal outcome in our previous study. Now we demonstrate AKI is a serious complication of DPLN with adverse long-term outcomes. Cox regression analyses showed a relationship between the increased severity of AKI and increased incidence of ESRD.

Systematic review with meta-analysis and recent observational studies demonstrated a reproducible association between AKI, subsequent CKD and ESRD [29-33]. The populations of these studies came from cardiovascular diseases, ICU, general surgical settings and general hospital settings and the causes of AKI in these patients usually were renal hypoperfusion, acute tubular injury or necrosis, renal artery stenosis and nephrotoxic drugs (such as contrast agents). Our study showed the association between AKI and ESRD in glomerulonephritis patients. Furthermore, the ROC curve confirmed the good discriminatory power of the KDIGO AKI classification in predicting long-term outcome of DPLN with AKI. Such analytical results (AUROC was $0.831, P<0.001$ ) suggest that AKI classification is a good tool for measuring disease severity in lupus patients with AKI. 


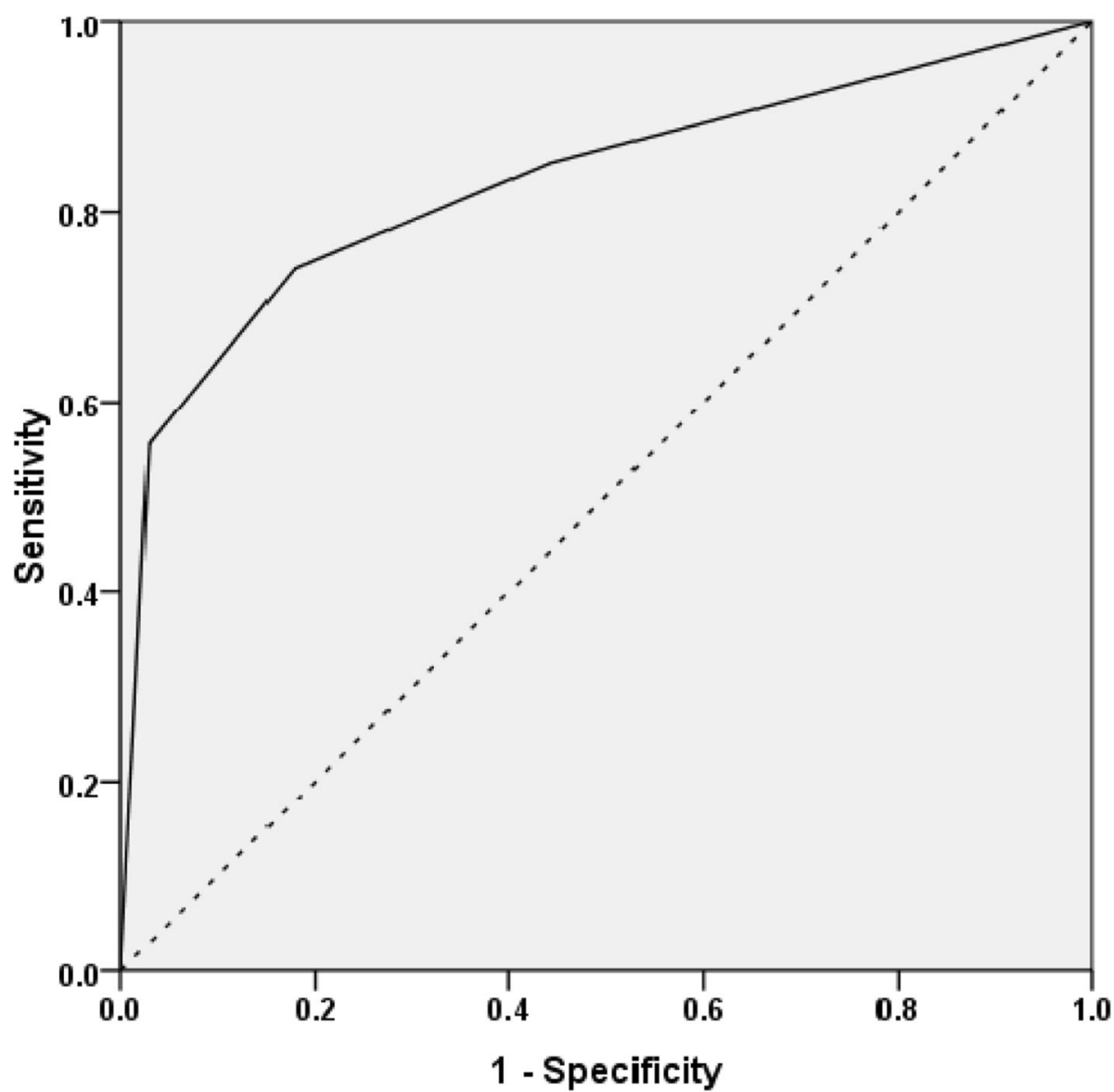

Fig. 2 ROC curves for AKI classification to predict primary outcome (AUROC curve is $0.831, P<0.001$ ). The sensitivity and specifity at the cut-off level of AKI-2 was 74 and $82 \%$

Table 4 Cox regression analyses-adjusted HR for for primary endpoint

\begin{tabular}{llll}
\hline variables & HR & 95\%confidence intervals & $P$-value \\
\hline AKI stage & 3.8 & $2.1-6.7$ & $<0.001$ \\
$C_{3}>0.4 \mathrm{mg} / \mathrm{dl}$ & 0.7 & $0.2-2.1$ & 0.49 \\
MP pulse treatment & 0.8 & $0.2-2.5$ & 0.68 \\
INS/PRN LN type IV + V & 0.9 & $0.7-1.2$ & 0.44 \\
INS/PRN active+chonic lesion & 1.1 & $0.3-3.5$ & 0.89 \\
great crescent> 30\% & 2.1 & $1.2-3.6$ & 0.008 \\
mBP $>115 \mathrm{mmHg}$ & 2.6 & $0.9-7.7$ & 0.081 \\
Hb $<8.0 \mathrm{~g} / \mathrm{dl} ;$;mean $\pm \mathrm{SD})$ & 4.8 & $1.6-14.0$ & 0.005 \\
Proteinuria> 3.0 g/d & 5.1 & $1.5-17.1$ & 0.008 \\
\hline AKI & &
\end{tabular}

$A K I$ acute kidney injury, $C_{3}$ serum complement component $3, M P$ methylprednisolone, $L N$ lupus nephritis; great crescent, is one of those extracapillary lesions that involves $>50 \%$ of the circumference of Bowman's capsule; great crescents $\geq 30 \%$, refers to patients with $>30 \%$ of the glomeruli containing great crescents; $\mathrm{mBP}$ mean blood presure, $\mathrm{Hb}$ hemoglobin
AKI is a heterogeneous syndrome with multiple potential causes and the outcomes may differ across different AKI etiologies, severity of primary disease and complications. Clinical settings of proteinuria and pathological changes will have an impact on outcomes in DPLN with AKI patients. Relative risks were particularly high in DPLN with AKI patients who had heavy proteinuria (24$\mathrm{h}$ urine protein $>3.0 \mathrm{~g}, \mathrm{HR}=5.1$ ). Besides, the multivariate Cox regression analysis revealed that anemia $(\mathrm{Hb}<$ $8.0 \mathrm{~g} / \mathrm{dl}, \mathrm{HR}=4.8$ ) and crescents (more than $30 \%, \mathrm{HR}=$ 2.1) were independent risk factors for ESRD. These risk factors were also reported in recent studies from Asian LN patients [34-36].

The most important limitation of this study was the study design. It was a retrospective observational study which is commonly affected by various sources of bias. It should be stressed, however, that the primary outcome (ESRD and death) was the hard endpoint and therefore unlikely to have been influenced by knowledge of patients' allocation. This study was not a clinical trial to evaluate therapeutic effect of drug intervention, so our doctors were not biased against certain groups of 
patients during follow-up. Second, this study was a relatively small size with Chinese patients rather than a large international multicenter study. Our small size study may over-estimated the magnitude of an association between risk factors and renal outcomes. The required sample size was 122 patients based on statistic power of a test $(80 \%)$ and type I error (5\%), so 167 patients in our study were sufficient to prognostic analysis of renal outcome using Cox regression model.

\section{Conclusions}

We found that each increase in severity of KDIGO AKI category was associated with an increase in progression to ESRD in DPLN patients. Analytical data also confirmed the good discriminative power of the KDIGO AKI classification system for predicting long-term prognosis of DPLN patients with AKI.

\section{Abbreviations}

AKI: Acute kidney injury; DPLN: Diffuse proliferative lupus nephritis; eGFR: Evaluated glomerular filtrition rate; ISN/RPS: International society of nephrology/renal pathology society; KDIGO: Kidney Disease: Improving Global Outcomes; LN: Lupus nephritis; SLE: Systemic lupus erythematosus

\section{Acknowledgments}

The study was supported by Wenzhou Science and Technology Bureau(Y20180697) , National Natural Science Foundation of China (81873949), Medical Innovation Discipline of Zhejiang Province (Critical Care Medicine,Y2015) and the Department of Nephrology, The First Affiliated Hospital of Wenzhou Medical University.

\section{Authors' contributions}

TC contributed to conception and design of the study, interpreted results and wrote this original article; YZ conducted all statistical analyses, JZ had data collection. CC and JP contributed to conception and design of the study and revised the manuscript. All authors read and approved the final manuscript.

\section{Funding}

The authors disclosed receipt of the following financial support for the research and/or publication of this article: Wenzhou Science and Technology Bureau (Y20180697), National Natural Science Foundation of China (81873949) and Medical Innovation Discipline of Zhejiang Province (Critical Care Medicine,Y2015). The funder did not play a role in study design, data collection, analysis, reporting, or the decision to submit for publication.

\section{Availability of data and materials}

The data that support the findings of this study were used under license for the current study from the First Affiliated Hospital of Wenzhou Medical University and are not publicly available. Data are, however, available from the authors upon reasonable request and with permission of the First Affiliated Hospital of Wenzhou Medical University.

\section{Ethics approval and consent to participate}

This is a retrospective observational study. The Ethics Committee of the First Affiliated Hospital of Wenzhou Medical University waived the need for an informed consent. Data were collected anonymously.

\section{Consent for publication}

Not applicable.

\section{Competing interests}

The authors declare that they have no competing interests.

\section{Author details}

'Department of Nephrology, The First Affiliated Hospital of Wenzhou Medical University, Wenzhou 325000, Zhejian Province, People's Republic of China. ${ }^{2}$ Department of ICU, The First Affiliated Hospital of Wenzhou Medical University, Wenzhou 325000, Zhejiang Province, People's Republic of China.

Received: 25 October 2019 Accepted: 30 December 2019

Published online: 13 January 2020

\section{References}

1. Saxena R, Mahajan T, Mohan C. Lupus nephritis: current update. Arthritis Res Ther. 2011;13:240

2. Jakes RW, Bae SC, Louthrenoo W, et al. Systematic review of the epidemiology of systemic lupus erythematosus in the Asia-Pacific region: prevalence, incidence, clinical features, and mortality. Arthritis Care Res (Hoboken). 2012;64:159-68.

3. Yap DYH, Tang CSO, Ma MKM, et al. Survival analysis and causes of mortality in patients with lupus nephritis. Nephrol Dial Transplant. 2012;27:3248-54.

4. Tektonidou MG, Dasgupta A, Ward MM. Risk of end-stage renal Disease in patients with lupus nephritis, 1971-2015: a systematic review and Bayesian meta-Analysis. Arthritis Rheumatol. 2016;68(6):1432-41.

5. Moroni G, Quaglini S, Maccario M. et al."nephritic flares" are predictors of bad long-term renal outcome in lupus nephritis. Kidney Int. 1996;50(6): 2047-53.

6. Chen YE, Korbet SM, Katz RS, et al. Value of a complete or partial remission in severe lupus nephritis. Clin J Am Soc Nephrol. 2008:3:46-53.

7. Chrysochou C, Randhawa H, Reeve R, et al. Determinants of renal functional outcome in lupus nephritis: a single Centre retrospective study. Q J Med. 2008;101:313-6.

8. Zhu D, Qu Z, Tan Y, Yu F, Zhao MH. Acute Kidney Injury in Chinese Patients with Lupus Nephritis: A Large Cohort Study From a Single Center. Lupus. 2011;20:1557-65.

9. Benseler SM, Bargman JM, Feldman BM, et al. Acute renal failure in paediatric systemic lupus erythematosus: treatment and outcome. Rheumatology. 2009:48(2):176-82.

10. Chen T, Ding X, Chen B. Value of the RIFLE classification for acute kidney injury in diffuse proliferative lupus nephritis. Nephrol Dial Transplant. 2009; 24(10):3115-20.

11. Kidney Disease: Improving Global Outcomes (KDIGO) Acute Kidney Injury Work Group. KDIGO Clinical Practice Guideline for Acute Kidney Injury. Kidney Int. 2012;3(1)suppl 2:1-138.

12. Selby NM, Taal MW. Long-term outcomes after AKI-a major unmet clinical need. Kidney Int. 2019;95(1):21-3.

13. Hochberg MC. Updating the American College of Rheumatology revised criteria for the classification of systemic lupus erythematosus. Arthritis Rheum. 1997:40:1725.

14. Weening JJ, D'Agati VD, Schwartz MM, et al. The classification of glomerulonephritis in systemic lupus erythematosus revisited. Am Soc Nephrol. 2004;15:241-50

15. Levey AS, Stevens LA, Schmid $\mathrm{CH}$, et al. A new equation to estimate glomerular filtration rate. Ann Intern Med. 2009;150:604-12.

16. Ponticelli C, Zucchelli P, Moroni G, Cagnoli L, Banfi G, Pasquali S. Long-term prognosis of diffuse lupus nephritis. Clin Nephrol. 1987;28(6):263-71.

17. Mok CC, Ying KY, Ng WL, et al. Long-term outcome of diffuse proliferative lupus glomerulonephritis treated with cyclophosphamide. Am J Med. 2006; 355:25-33.

18. Hahn BH, McMahon MA, Wilkinson A, et al. American College of Rheumatology. American College of Rheumatology guidelines for screening, treatment, and management of lupus nephritis. Arthritis Care Res (Hoboken). 2012;64:797-808.

19. Bertsias GK, Tektonidou M, Amoura Z, et al. Joint European league against rheumatism and European renal association-European Dialysis and transplant association (EULAR/ERA-EDTA) recommendations for the management of adult and paediatric lupus nephritis. Ann Rheum Dis. 2012; 71:1771-82

20. Kidney Disease: Improving Global Outcomes (KDIGO) Glomerulonephritis Work Group. KDIGO clinical practice guidelines for glomerulonephritis. Kidney Int. Suppl. 2012;2:139-274

21. Chan TM, Li FK, Tang CS, et al. Efficacy of mycophenolate mofetil in patients with diffuse proliferative lupus nephritis. N Engl J Med. 2000;343:1156-62. 
22. IIlei G, Austin HA III, Crane M, et al. Combination therapy with pulse cyclophosphamide plus pulse methylprednisolone improves long-term renal outcome without adding toxicity in patients with lupus nephritis. Ann Intern Med. 2001;135:248-57.

23. Yee C-S, Gordon C, Dostal C, et al. EULAR randomized controlled trial of pulse cyclophosphamide and methylprednisolone versus continuous cyclophsphamide and prednisolone followed by azathioprine and prednisolone in lupus nephritis. Ann Rheum Dis. 2003;63:525-9.

24. Contreras G, Pardo V, Leclercq B, et al. Sequential therapies for proliferative lupus nephritis. N Engl J Med. 2004;350:971-80.

25. McKinley A, Park E, Spetie DN, Hackshaw K, et al. Oral cyclophosphamide for lupus glomerulonephritis: an under-utilized therapeutic option. Clin J Am Soc Nephrol. 2009;4(11):1754-60.

26. Appel GB, Contreras G, Dooley MA, et al. Mycophenolate mofetil versus cyclophosphamide for induction treatment of lupus nephritis. J Am Soc Nephrol. 2009;20:1103-12.

27. Tektonidou M, Dasgupta A, Ward M. Risk of end-stage renal disease in patients with lupus nephritis, 1970-2015: a systematic review and Bayesian meta-analysis. Arthritis Rheumatol. 2016;68:1432-41.

28. Moroni G, Quaglini S, Gallelli B, et al. The long-term outcome of 93 patients with proliferative lupus nephritis. Nephrol Dial Transplant. 2007;22:2531-9.

29. Coca SG, Singanamala S, Parikh CR. Chronic kidney disease after acute kidney injury: a systematic review and meta-analysis. Kidney Int. 2012;81:442-8.

30. Pannu NJames M, Hemmelgarn B, Klarenbach S. Alberta kidney Disease network. Association between AKI, recovery of renal function, and long-term outcomes after hospital discharge. Clin J Am Soc Nephrol. 2013;8:194-202.

31. Chawla LS, Eggers PW, Star RA, Kimmel PL. Acute kidney injury and chronic kidney disease as interconnected syndromes. N Engl J Med. 2014;371:58-66.

32. Chew ST, Ng RR, Liu W, et al. Acute kidney injury increases the risk of endstage renal disease after cardiac surgery in an Asian population: a prospective cohort study. BMC Nephrol. 2017;18:60.

33. See EJ, Jayasinghe K, Glassford N, et al. Long-term risk of adverse outcomes after acute kidney injury: a systematic review and meta-analysis of cohort studies using consensus definitions of exposure. Kidney Int. 2019;95:160-72.

34. Cai F, Han F, Wang H, Han H, Le J, Lan L, Xu Y, Chen J. The Crescentic implication of renal outcomes in proliferative lupus nephritis. J Rheumatol. 2018;45(4):513-20

35. Zhang W, Yuan M, Hong L, Zhou Q, Chen W, Yang S, Yang Q, Chen W, Yu $X$. Clinical outcomes of lupus nephritis patients with different proportions of crescents. Lupus. 2016;25(14):1532-41.

36. Ichinose K, Kitamura M, Sato S, Fujikawa K, Horai Y, Matsuoka N, Tsuboi M, Nonaka F, Shimizu T, Fukui S, Umeda M, Koga T, Kawashiri S, Iwamoto N, Tamai M, Nakamura H, Origuchi T, Nishino T, Kawakami A. Factors predictive of long-term mortality in lupus nephritis: a multicenter retrospective study of a Japanese cohort. Lupus. 2019;28(3):295-303.

\section{Publisher's Note}

Springer Nature remains neutral with regard to jurisdictional claims in published maps and institutional affiliations.

Ready to submit your research? Choose BMC and benefit from:

- fast, convenient online submission

- thorough peer review by experienced researchers in your field

- rapid publication on acceptance

- support for research data, including large and complex data types

- gold Open Access which fosters wider collaboration and increased citations

- maximum visibility for your research: over $100 \mathrm{M}$ website views per year

At $\mathrm{BMC}$, research is always in progress.

Learn more biomedcentral.com/submissions 